\title{
Coronal Leakage Inhibition in Endodontically Treated Teeth Using Resin-coating Technique
}

\author{
Rena MARUOKA ${ }^{1}$, Toru NIKAIDO $^{1}$, Masaomi IKEDA ${ }^{1}$, Tomoyasu ISHIZUKA ${ }^{2}$, Richard M. FOXTON ${ }^{3}$ \\ and Junji TAGAMI ${ }^{1,4}$ \\ ${ }^{1}$ Cariology and Operative Dentistry, Department of Restorative Sciences, Graduate School, Tokyo Medical and Dental Univer- \\ sity, 1-5-45 Yushima, Bunkyo-ku, Tokyo, 113-8549, Japan \\ ${ }^{2}$ Pulp Biology and Endodontics, Department of Restorative Sciences, Graduate School, Tokyo Medical and Dental University, \\ 1-5-45 Yushima, Bunkyo-ku, Tokyo, 113-8549, Japan \\ ${ }^{3}$ Department of Conservative Dentistry, King's College London Dental Institute at Guy's, King's College and St. Thomas' \\ Hospitals, London, SE1-9RT, UK \\ ${ }^{4}$ Center of Excellence Program for Frontier Research of Molecular Destruction and Reconstruction of Tooth and Bone, Tokyo \\ Medical and Dental University, 1-5-45 Yushima, Bunkyo-ku, Tokyo, 113-8549, Japan \\ Corresponding author, Rena Maruoka E-mail:maruoka.ope@tmd.ac.jp
}

Received September 22, 2005/Accepted December 5, 2005

\begin{abstract}
The purpose of this study was to evaluate coronal leakage inhibition using a resin-coating technique after endodontic treatment. Thirty-six human incisors were cut at the cementoenamel junction, and endodontic obturations were performed. The specimens were randomly divided into three groups according to post space preparation (10 $\mathrm{mm}$ depth), resin coating, and temporization. For the resin coating, the dentin surface was coated with either a combination of Clearfil SE Bond and Protect Liner F (SE/PLF) or RZII (RZ). Then, the specimens were stored in $37^{\circ} \mathrm{C}$ distilled water for 24 hours and placed in $1 \%$ methylene blue solution for 48 hours. After which, the specimens were sectioned faciolingually along the root canal and the length of dye penetration was measured from the cementoenamel junction. Three-way ANOVA revealed that the dye penetration scores were influenced by post space preparation, resin coating, and temporization. Resin coating with RZ significantly reduced the dye penetration score and SE/PLF completely eliminated dye penetration.
\end{abstract}

Key words: Resin coating, Coronal leakage, Endodontically-treated teeth

\section{INTRODUCTION}

Recent advances in adhesive technology have made direct placement of composite resin restorations a commonplace treatment procedure in clinical dentistry. Direct composite restorations are the preferred treatment over indirect composite restorations because they require minimal intervention and cavity preparation ${ }^{1)}$. Dentin adhesives can be applied not only to vital teeth but also to non-vital teeth. It has been extensively reported that recent dentin adhesive systems can bond to root canal dentin ${ }^{2,3)}$ and pulpal floor dentin ${ }^{4,5)}$ as well as to coronal dentin. However, the chemical irrigants and medicaments used during root canal treatment are the clinical factors that influence bonding to dentin in direct and indirect restorations ${ }^{6,7)}$.

Endodontic obturation can provide an effective apical seal. However, the apical seal can be adversely affected once the coronal restoration is lost or becomes defective. Significant coronal dye penetration has been shown to occur following dissolution of the sealer by artificial saliva ${ }^{8,9)}$. Dissolution of the sealer allows access of periapical fluids, proteins, and bacteria to the root canal. Fractured teeth and leaking/ lost temporary restorations are often encountered clinically, which can leave the root canal filling open to the oral cavity. Therefore, the quality of the coronal seal is equally important for the ultimate success of any root canal obturation since endodontic sealers do not bond well to dentin.

In the case of indirect restorations, resin cement has become widely accepted for luting tooth-colored restorations. However, the dentin bonding ability of resin cements is lower than that of resin adhesives. Therefore, new methods are urgently needed to improve the dentin bonding ability of contemporary resin cements to obtain optimum indirect restorations.

A resin-coating technique has recently been developed in which both a hybrid layer and a tight sealing film are produced on the dentin surface ${ }^{10)}$. In this technique, a resin coating of a dentin adhesive system and a low-viscosity microfilled resin are recommended to be applied to the prepared cavity immediately after tooth preparation and just before taking impression. However, the combination of a dentin bonding system and a low-viscosity microfilled resin creates a thick coating layer on the dentin surface ${ }^{11)}$, which is not appropriate for crown preparations.

Recently, a thin-film coating material has been developed through advancement in single-step bonding technology ${ }^{12)}$. It was reported that the thin-film coating material could improve the dentin bonding 
performance of the resin cement ${ }^{12)}$, as well as prevent marginal leakage beneath full cast crowns ${ }^{13)}$.

This technique has the ability to minimize pulpal irritation caused by mechanical and thermal stimuli and bacterial infiltration in vital teeth ${ }^{10)}$. Nonetheless, the technique can also be applied in the restoration of non-vital teeth. Therefore, the purpose of this study was to evaluate the effect of resin coating on coronal leakage inhibition in endodontically treated teeth. In addition, the influences of post space preparation and temporization on coronal leakage were evaluated.

\section{MATERIALS AND METHODS}

Materials used in this study

The materials used in this study are listed in Table 1. For the resin coating, a combination of Clearfil SE Bond and Protect Liner F (Kuraray Medical, Tokyo, Japan) or a single coat of an experimental material, RZII (Sun Medical, Moriyama, Japan), was applied to dentin. Clearfil SE Bond is a two-step self-etching primer system, and Protect Liner $\mathrm{F}$ is a microfilled resin. The combination of Clearfil SE Bond and Protect Liner $F$ has been reported to be one of the optimal combinations for resin coating of cavity preparations ${ }^{14,15)}$. On the other hand, RZII is an experimental single-step bonding material. It creates a thin film $(5-6 \mu \mathrm{m})$ on the dentin surface, which is appropriate for the resin coating of crown preparations ${ }^{12)}$.

Previous studies have demonstrated that a watersetting temporary filling material, Cavit-G (3M ESPE, Seefeld, Germany), is an appropriate temporary filling for the resin-coating technique ${ }^{16)}$.

\section{Specimen preparation}

Specimen preparation is illustrated in Fig. 1. Thirtysix extracted, single-canal, human incisors stored in distilled water within three months of extraction were used. All the teeth were cut at the level of the cementoenamel junction with a diamond bur (ISO \#173016, GC, Tokyo, Japan). Standard endodontic access cavities were made and the root canal contents were removed with \#15-\#35 K-type files (Zipperer, VDW, Monachium, Niemcy). Patency of the apical foramen was determined using a \#35 K-type file. Working length was established $0.5 \mathrm{~mm}$ short of the length at which this file exited the foramen, ensuring that the apical preparation was complete to within 1 $\mathrm{mm}$ of the apical foramen. The canals were irrigated with $3 \%$ sodium hypochlorite and chemomechanically prepared to a \#35 master apical file. Then, the canals were dried with paper points followed by apical cleaning. Master gutta-percha cones (GC, Tokyo, Japan) were fitted to within $1 \mathrm{~mm}$ of the working length in the 36 teeth. The cones were coated with Sealapex (Kerr, Orange, U.S.A.), placed in the canals, and condensed by cold lateral condensation. Excess gutta-percha was removed with a heated hand instrument at the level of the cementoenamel junction. After obturation, the coronal openings were covered with the temporary filling material, Cavit-G, while the apical foramens were sealed with utility wax. Following this, the specimens were placed in water at $37^{\circ} \mathrm{C}$ for 24 hours to allow the sealer to set.

Specimens were randomly divided into three groups of twelve according to the following factors: post space preparation, resin coating, and temporization. Post space preparation was carried out in half of the specimens and no preparation was done in the remaining specimens. Post spaces, $10 \mathrm{~mm}$ in length, were prepared from the cementoenamel junction using a post preparation bur (Size 25, 0.05 taper, GC, Tokyo, Japan). For each group, the specimens were divided into two subgroups - with or without resin coating. For the resin coating subgroups, the dentin surface was coated with either a combination of Clearfil SE Bond and Protect Liner F (SE/PLF) or one coat of RZII according to the manufacturer's instructions. Light-curing unit used in this study was New Light-VL-II (GC Co., Tokyo, Japan). Each sub-

Table 1 Manufacturers' instructions on the bonding procedures for resin coating, bonding system, and low-viscosity microfilled resin

\begin{tabular}{|c|c|c|c|}
\hline Material (Batch No.) & Components & Chemical composition & Directions \\
\hline Clearfil SE Bond (003A) & $\begin{array}{l}\text { Primer } \\
\text { Bond }\end{array}$ & $\begin{array}{l}\text { MDP, HEMA, photoinitiator, water, functional } \\
\text { monomer } \\
\text { MDP, HEMA, Bis-GMA, microfiller, water, } \\
\text { functional monomer }\end{array}$ & $\begin{array}{l}20 \text { seconds apply, dry } \\
10 \text { seconds light-cure }\end{array}$ \\
\hline RZII（010410） & $\begin{array}{l}\text { Liquid } \\
\text { Sponge }\end{array}$ & $\begin{array}{l}\text { Water, acetone, 4-META, polyfunctional acrylate, } \\
\text { monomethacrylate, photoinitiators, stabilizers } \\
\text { p-toluenesulfinate, amine }\end{array}$ & $\begin{array}{l}\text { Mix sponge and liquid, } \\
\text { apply, dry } \\
10 \text { seconds light-cure }\end{array}$ \\
\hline Protect Liner F (0003) & & $\begin{array}{l}\text { Microfiller }\left(\mathrm{SiO}_{2}\right) \text {, MF-MMA copolymer, } \\
\text { dimethacrylate monomer, catalyst }\end{array}$ & 20 seconds light-cure \\
\hline Cavit-G (0311) & & $\begin{array}{l}\text { Zinc oxide, calcium sulfate, zinc sulfate, glycol } \\
\text { acetate, polyvinyl acetate, polyvinyl chlorite } \\
\text { acetate, triethanolamine }\end{array}$ & \\
\hline
\end{tabular}


group was further divided into two groups, where the coronal opening was either covered with or without the temporary filling material, Cavit-G.

\section{Dye penetration test}

Entire tooth surfaces were coated with nail varnish, leaving only the coronal openings exposed. The apical parts were sealed with utility wax. The teeth were then placed in $1 \%$ methylene blue solution for 48 hours before they were sectioned into two halves faciolingually using a water-cooled diamond saw (Leitz1600, Wetzlar, Germany). Dye penetration measurement was carried out to the nearest $0.01 \mathrm{~mm}$ using a stereomicroscope (Olympus Colposcope, Olympus Optical Japan, Tokyo, Japan) at $\times 3$ magnification. Linear dye penetration along the facial and lingual sides of the root canal was measured from the cementoenamel junction for the specimens without post space preparation, while measurement was performed from the surface of the post space preparation for the specimens with post space preparations ${ }^{17)}$.

\section{Statistics}

Number of specimens in each group was three. Mean dye penetration score achieved by each group were compared using one- and three-way ANOVA and Scheffe's test at a 95\% confidence interval except for the SE/PLF group, which demonstrated no dye penetration. The three evaluation factors were post space preparation, resin coating, and temporization.

\section{RESULTS}

Results of the dye penetration test are summarized in Table 2 and Fig. 2. Statistical analysis of the results is summarized in Table 3. Three-way ANOVA revealed that coronal leakage was influenced by resin coating $(F=161.311 ; p<0.0001)$, post space preparation $(F=10.257 ; p<0.006)$, and temporization $(F=$ coating

$(-)$

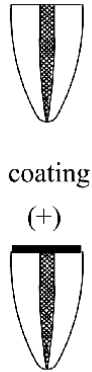

coating

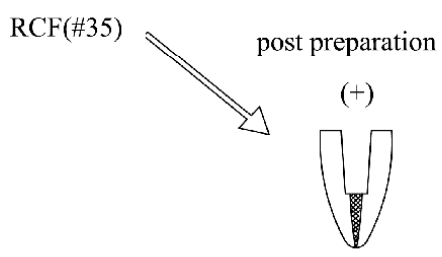

$(-)$<smiles>C=CC</smiles><smiles>C[SiH2]C</smiles>

$(-)$

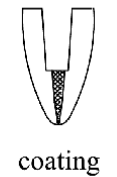

coating

$(+)$

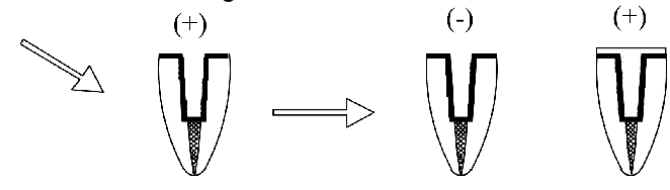

temporization

$(-)$

$(+)$

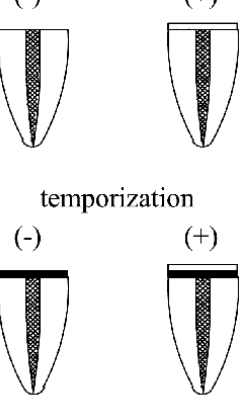

temporization

$(-)$

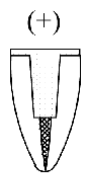

$(-)$

Fig. 1 Schematic illustration of the specimens' preparation procedures.

Table 2 Mean dye penetration measurements (in $\mathrm{mm}$ )

\begin{tabular}{|c|c|c|c|c|}
\hline \multirow{2}{*}{ Post space preparation } & \multirow{2}{*}{ Temporization } & \multirow{2}{*}{ No coating } & \multicolumn{2}{|c|}{ Coating } \\
\hline & & & RZII & $\mathrm{SE} / \mathrm{PLF}$ \\
\hline \multirow{2}{*}{-} & - & $1.74 \pm 0.50$ & $0.28 \pm 0.26$ & n. d. \\
\hline & + & $0.92 \pm 0.09$ & $0.11 \pm 0.07$ & n. d. \\
\hline \multirow{2}{*}{+} & - & $2.17 \pm 0.19$ & $0.26 \pm 0.26$ & n. d. \\
\hline & + & $1.78 \pm 0.21$ & $0.19 \pm 0.16$ & n. d. \\
\hline
\end{tabular}




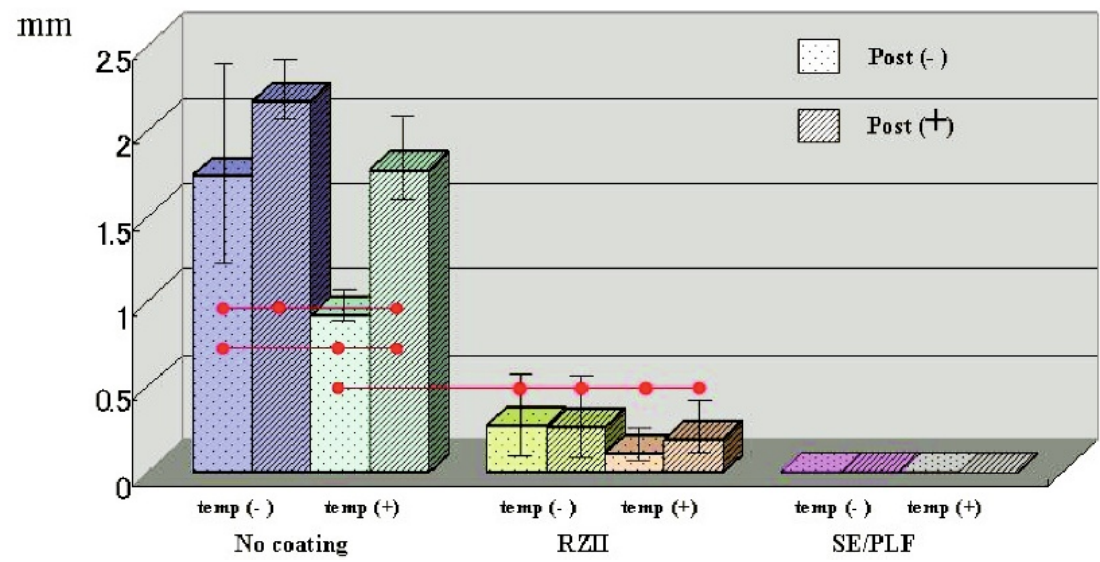

Fig. 2 Bar charts representing mean dye penetration measurements. Red lines on graph mean they do not have a significant difference.

(a)

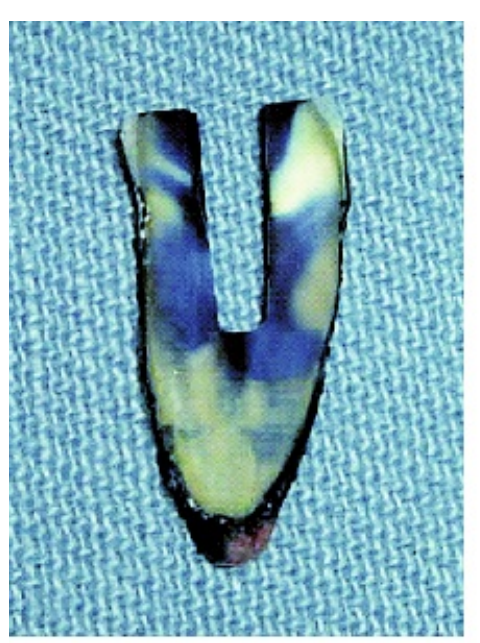

(c)

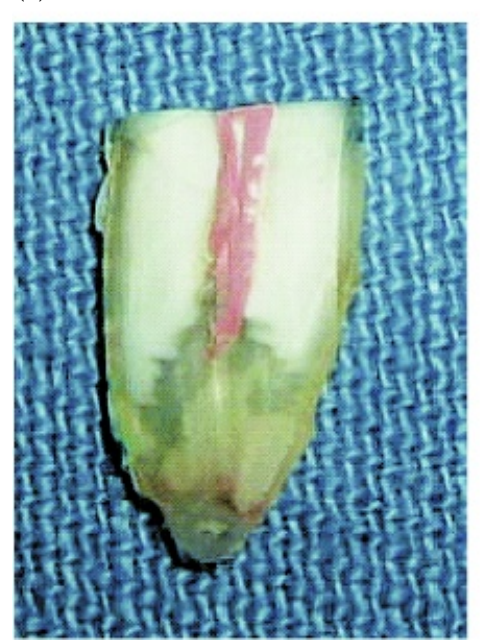

(b)

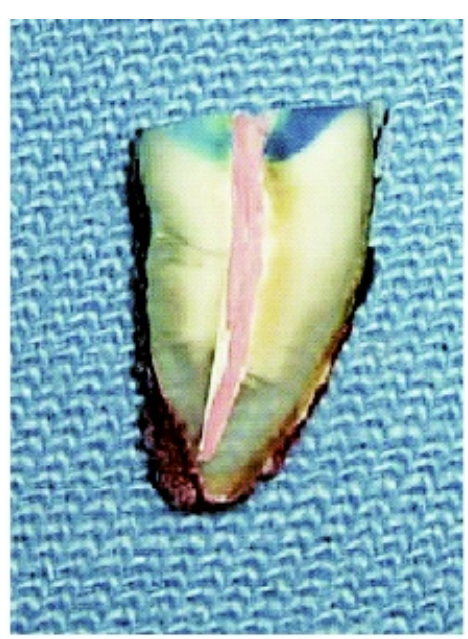

(d)

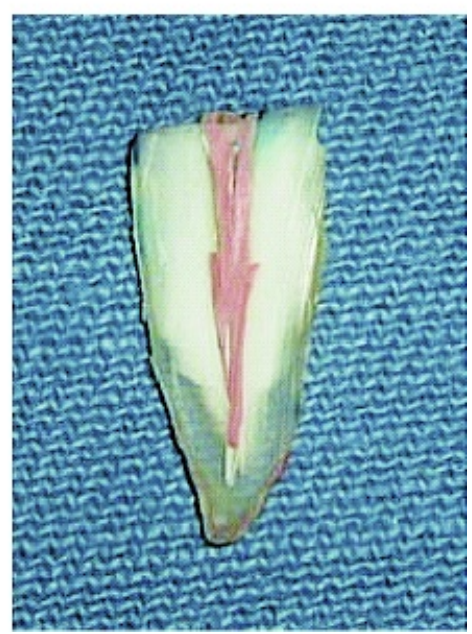

Fig. 3 Representative stereoscope photographs of the no coating/post group (a), no coating/no post group (b), SE/PLF coating/no post group (c), and RZII coating/no post group (d). 
Table 3 Results of the statistical analysis

\begin{tabular}{lcc}
\hline & F-value & Significant probability \\
\hline Resin coating & 161.311 & $<0.0001$ \\
Post space preparation & 10.257 & 0.006 \\
Temporization & 8.81 & 0.009 \\
Resin coating * Post space preparation & 4.548 & 0.049 \\
Resin coating *Temporization & 7.234 & 0.016 \\
Post space preparation *Temporization & 1.257 & 0.279 \\
\hline
\end{tabular}

8.810; $p<0.009)$.

Only the SE/PLF group's specimens demonstrated no coronal leakage. All the RZII-coated groups exhibited coronal leakage except for one specimen. In particular, non-coated specimens showed greater dye penetration regardless of temporization and post space preparation.

Representative specimens after the dye penetration test are shown in Fig. 3. For the no coating/ post space preparation group (a) and no coating/no post group (b), methylene blue was highly visible between the laterally condensed gutta-percha cones in the dentinal tubules, and between the gutta-percha and canal walls. For the SE/PLF coating group (c), no staining was observed. For the RZII coating group (d), slight dye penetration was observed along the root canal. In addition, the coating material itself was stained - thereby indicating possible dye penetration through the material.

\section{DISCUSSION}

Obtaining a hermetic seal is one of the keys to achieving a successful long-term root filling. However, a hermetic seal cannot be obtained if root canal filling materials do not bond to the dentin walls ${ }^{18,19)}$. Several methods have been reported to prevent coronal leakage through obturated root canals in the event that the coronal restoration becomes defective or lost. These include placement of an additional material into the canal orifice after removal of part of the gutta-percha and sealer, sealing the entire chamber floor with a restorative material, or use of a root canal filling method that provides a seal without the addition of other sealing materials ${ }^{20)}$. Ideally, it would be that the root canal obturation alone could prevent coronal leakage, since no extra steps would then be required.

To evaluate dye penetration, methylene blue solution was chosen as a tracer in this study. Previously, several dye solutions, such as nitric acid ${ }^{8)}$, pelican ink $^{9,20)}$, india ink $^{21)}$, and methylene blue dye solution $^{19,22-24)}$, have been used for the dye penetration test. Although there is no universally accepted solution, $0.2-2.0 \%$ methylene blue solutions have been commonly used for dye penetration experiments in leakage studies $^{25,26)}$.
In the present study, higher coronal leakage occurred in the non-coated groups. The post space preparation group demonstrated significantly higher dye penetration than the non-preparation group. It is desirable that during post space preparation, the root canal sealer/gutta-percha and root canal sealer/root dentin interfaces be stabilized without dislodgement or loss of seal. However, post space preparation stimulates a gap between the root and root canal filling material ${ }^{27)}$. Moreover, a post space preparation shortens the distance from the root opening to the apex, thereby increasing the risk of coronal leakage.

Temporization does not provide a sufficient marginal seal. Cavit-G was used as a temporary filling in this study. Previously, the effect of temporary filling materials on bond strength to a resin-coated surface was evaluated after removal of the temporary filing materials ${ }^{16)}$. Highest bond strengths were obtained when Cavit-G was used as the temporary filling material. Cavit- $G$ reduces mixing inconsistencies commonly encountered during chairside manipulation. However, such a hygroscopic material tends to absorb fluids, which can be demonstrated by dye penetration into the filling material ${ }^{28)}$. Therefore, temporary fillings can delay the progress of dye penetration but not inhibit coronal leakage.

Application of a resin coating to the coronal openings significantly reduced coronal leakage scores. Perfect sealing was demonstrated by a combination of Clearfil SE Bond and Protect Liner F. It was reported that the resin-coating technique could minimize gap formation at the interface of MOD inlay restorations using a combination of a two-step selfetching primer adhesive system and a flowable microfilled resin ${ }^{11)}$. Clearfil SE Bond is a two-step self-etching primer adhesive system, which has demonstrated good dentin bond performance with direct composite restorations ${ }^{15)}$. An acidic monomer, MDP, in $\mathrm{SE}$ primer dissolves the smear layer and demineralizes the underlying dentin, thus resulting in mild surface etching ${ }^{29)}$. With the resin-coating technique, a suitable combination of a dentin bonding system and a low-viscosity microfilled resin can improve adhesion to dentin ${ }^{30}$. Further, the additional application of a low-viscosity microfilled resin can protect and promote polymerization of the underly- 
ing adhesive, hence resulting in increased bond strength ${ }^{31)}$.

In this study, the post space was $10 \mathrm{~mm}$ long and therefore light may not reach the lower portion of the post space. Consequently, in the RZII coating groups, the lower portion might not have been sufficiently polymerized and hence dye penetration occurred. Since the behavior of these coating materials in a clinical situation was the purpose of this study, the effect of polymerization shrinkage was also studied.

The experimental material, RZII, is a single-step resin coating material. Thickness of a single application of RZII is approximately $5-6 \mu \mathrm{m}$. Therefore, the development of RZII was aimed at resin-coating crown preparations ${ }^{32)}$. It was reported that the application of RZII to crown preparations significantly reduced microleakage ${ }^{13)}$. However, it has been pointed out that the bonding performance of all-inone adhesive systems to dentin needs to be somewhat improved $^{33)}$. It was reported that an all-in-one adhesive system acted as a semi-permeable membrane, which could be permeable to water ${ }^{34)}$. Therefore, RZII might have allowed methylene blue dye solution to penetrate through the RZII adhesive, thereby resulting in an increase in the dye penetration score.

Differences in regional bond strength could be attributed to the type of bonding system used, whereby photocure adhesive systems seemed to be effective on root canal dentin ${ }^{35)}$. However, irradiation time influences adhesion to root canal dentin when using photocure adhesive resins, because light irradiation from the orifice of the post cavity to the apical region is limited. Light irradiation for Clearfil SE Bond and RZII was performed according to the manufacturers' recommendations in this study. However, extending the irradiation time for the adhesives might enhance the mechanical properties of the adhesive resins, resulting in better sealing and a reduction in coronal leakage at the apical region.

Ray \& Trope investigated the relationship between the quality of coronal restoration and that of root canal obturation on the radiographic periapical status of endodontically treated teeth ${ }^{36)}$. Their results demonstrated that coronal restoration quality was statistically correlated to the presence of periradicular inflammation more than the quality of endodontic treatment. Therefore, the sealing ability of coronal restorations significantly affects the prognosis of endodontic treatment. The current study demonstrated that the resin-coating technique inhibited coronal leakage in endodontically treated teeth.

Until recently, non-vital teeth were usually treated with a crown, core, and/or dowel often leading to the sacrifice of sound tooth structure ${ }^{37)}$. A post space is prepared to gain mechanical retention of the core, meaning further removal of sound tooth substance. In the case of a post and core system, a greater degree of stress may be concentrated in the root $^{38,39)}$. These factors may adversely affect the longevity of a non-adhesively restored tooth. If good retention can be obtained using a dentin bonding system, a post may not be necessary, therefore preserving sound tooth structure. From a clinical standpoint, the resin-coating technique has strong possibilities for minimizing coronal leakage and removal of sound tooth structure, resulting in the achievement of minimally invasive restorations for non-vital teeth.

\section{ACKNOWLEDGEMENTS}

This study was supported by a Grant-in-aid (No. 15209064) from the Ministry of Education, Culture, Sports, Science and Technology of Japan and a research grant from the Center of Excellence Program for Frontier Research on Molecular Destruction and Reconstruction of Tooth and Bone at Tokyo Medical and Dental University.

\section{REFERENCES}

1) Tyas MJ, Anusavice KJ, Frencken JE, Mount GJ. Minimal intervention dentistry. Int Dent $J$ 2000; 50: 112.

2) Foxton RM, Nakajima M, Tagami J, Miura H. Bonding of photo and dual-cure adhesives to root canal dentin. Oper Dent 2003; 28: 543-551.

3) Kanno T, Ogata M, Foxton RM, Nakajima M, Tagami J, Miura H. Microtensile bond strength of dual-cure resin cement to root canal dentin with different curing strategies. Dent Mater J 2004; 23: 550-556.

4) Akagawa H, Nikaido T, Takada T, Burrow MF, Tagami J. Shear bond strengths to coronal and pulp chamber floor dentin. Am J Dent 2002; 15: 383-388.

5) Toba S, Veerapravati W, Shimada Y, Nikaido T, Tagami J. Micro-shear bond strengths of adhesive resins to coronal dentin versus the floor of the pulp chamber. Am J Dent 2003; 16: 51A-56A.

6) Nikaido T, Takano Y, Sasafuchi Y, Burrow MF, Tagami J. Bond strengths to endodontically treated teeth. Am J Dent 1999; 12: 177-180.

7) Sasafuchi Y, Nikaido T, Tagami J. Effect of chemical irrigants and medicaments for endodontic treatment on dentin bonding. Int Chin J Dent 2003; 3: 7-12.

8) Swanson K, Madison S. An evaluation of coronal microleakage in endodontically treated teeth. Part 1: Time periods. J Endodon 1987; 13: 56-59.

9) Madison S, Swanson K, Chiles SA. An evaluation of coronal microleakage in endodontically treated teeth. Part 2: Sealer types. J Endodon 1987; 13: 109-112.

10) Kitasako $Y$, Burrow MF, Nikaido T, Tagami J. Effect of resin-coating technique on dentin tensile bond strengths over 3 years. J Esthet Restor Dent 2002; 14: 115-122.

11) Jayasooriya PR, Pereira PNR, Nikaido T, Burrow MF, Tagami J. The effect of a "resin coating" on the inter- 
facial adaptation of composite inlays. Oper Dent 2003; 28: 28-35.

12) Nikaido T, Nakaoki Y, Ogata M, Foxton RM, Tagami J. The resin-coating technique: Effect of a single-step bonding system on dentin bond strengths. J Adhes Dent 2003; 5: 293-300.

13) Kosaka S, Kajihara H, Kurashige H, Tanaka T. Effect of resin coating as a means of preventing marginal leakage beneath full cast crowns. Dent Mater J 2005; 24: $117-122$.

14) Nikaido $T$, Cho E, Nakazima $M$, Tashiro $H$, Toba $S$, Burrrow MF, Tagami J. Tensile bond strengths of resin cements to bovine dentin using resin coating. Am J Dent 2003; 16: 41A-47A.

15) Jayasooriya PR, Pereira PNR, Nikaido T, Tagami J. Efficacy of a resin coating on bond strengths on resin cement to dentin. J Esthet Restor Dent 2003; 15: 105113.

16) Nakano M, Takada T, Nikaido T, Tagami J. Effect of impression material on adhesion of resin cement to resin coated teeth. J Jpn Adhes Dent 1999; 17: 198-204.

17) Wahab FK, Shaini FJ, Morgano SM. The effect of thermocycling on microleakage of several commercially available composite Class $\mathrm{V}$ restorations in vitro. J Prosthet Dent 2003; 90 (2): 168-174.

18) Skinner RL, Himel VT. The sealing ability of injection-molded thermoplasticized gutta-percha with and without the use of sealers. J Endodon 1987; 13: 315317.

19) Malone III KH, Donnelly JC. An in vitro evaluation of coronal microleakage in obuturated root canals without coronal restorations. J Endodon 1997; 23: 35-38.

20) Madison S, Wilcox LR. An evaluation of coronal microleakage in endodontically treated teeth. Part 3: In vivo study. J Endodon 1988; 14: 455-458.

21) Howdle MD, Fox K, Youngson CC. An in vitro study of coronal microleakage around bonded amalgam coronal-radicular cores in endodontically treated molar teeth. Quint Int 2002; 33: 22-29.

22) Beckham BM, Anderson RW, Morris CF. An evaluation of three materials as barriers to coronal microleakage in endodontically treated teeth. J Endodon 1993; 19: 388-391.

23) Vizgirda PJ, Liewehr FR, Patton WR, McPherson JC, Buxton TB. A comparison of laterally condensed gutta-percha, thermoplasticized gutta-percha, and mineral trioxide aggregate as root canal filling materials. J Endodon 2004; 2: 103-106.

24) Piemjai M, Watanabe A, Iwasaki $Y$, Nakabayashi N. Effect of remaining demineralised dentin on dental microleakage accessed by a dye penetration: How to inhibit microleakage? J Dent 2004; 32: 495-501.

25) Wu MK, Wesselink PR. Endodontic leakage studies reconsidered. Part I: Methodology, application and relevance. Int Endod J 1993; 26: 37-43.

26) Wu MK, Kontakiotis EG, Wesselink PR. Decoloration of $1 \%$ methylene blue solution in contact with dental filling materials. J Dent 1998; 26: 585-589.

27) Saunders EM, Saunders WP, Rashid MY. The effect post preparation on the apical seal of root fillings using chemically adhesive materials. Int Endod J 1991; 24: $51-57$.

28) Cruz EV, Shigetani Y, Ishikawa K, Kota K, Iwaku M, Goodis HE. A laboratory study of coronal microleakage using four temporary restorative materials. Int Endod J 2002; 35: 315-320.

29) Jacques P, Hebling J. Effect of dentin conditioners on the microtensile bond strength of a conventional and a self-etching primer adhesive system. Dent Mater 2005; 21: $103-109$.

30) Nikaido $\mathrm{T}$, Kunzelmann $\mathrm{KH}$, Chen $\mathrm{H}$, Ogata $\mathrm{M}$, Harada N, Yamaguchi S, Cox CF, Hickel R, Tagami J. Evaluation of thermal cycling and mechanical loading on bond strength of a self-etching primer system to dentin. Dent Mater 2002; 18: 269-275.

31) Jayasooriya PR, Pereira PNR, Nikaido T, Tagami J. Micro-tensile bond strengths of resin cement to dentin using resin-coating technique. J Dent Res 2001; 80 (Special Issue), Abstract \#1818, p.754.

32) Nikaido T, Nakaoki Y, Ogata M, Tagami J. Dentin bonding of a new single-step bonding system for "resin coating". J Jpn Adhes Dent 2003; 21: 99-105.

33) Perdigao J, Frankenberger R, Rosa BT, Breschi L. New trends in dentin/enamel adhesion. Am $J$ Dent 2000; 13: 25D-30D.

34) Tay FR, Pashley DH. Water treeing - potential mechanism for degradation of dentin adhesives. Am J Dent 2003; 16: 6-12.

35) Aksornmuang J, Nakajima M, Foxton RM, Tagami J. Regional bond strength of four self-etching primer/adhesive systems to root canal dentin. Dent Mater J 2005; $24(2)$ : 261-267.

36) Ray HA, Trope M. Periapical status of endodontically treated teeth in relation to the technical quality of the root filling and the coronal restoration. Int Endod $\mathrm{J}$ 1995; 28: 12-18.

37) Wagnild GW, Mueller KI. Restoration of the endodontically treated tooth. In: Pathways of the pulp, $8^{\text {th }}$ ed, St Louis, Mosby, 2000, pp.765-795.

38) Sornkul E, Stannard JG. Strength of roots before and after endodontic treatment and restoration. J Endodon 1992; 18: 440-443.

39) Mount GJ, Ngo H. Minimal intervention: A new concept for operative dentistry. Quint Int 2000; 31: 527533. 